\title{
Avaliatividade verbal e visual em textos que divulgam pesquisas de opinião pública ${ }^{1}$ Verbal and visual appraisal in texts publishing public opinion research
}

\author{
Cristiane Salete Florek ${ }^{2}$ \\ Sara Regina Scotta Cabral ${ }^{3}$
}

\section{RESUMO}

Objetivamos investigar posicionamentos avaliativos em textos multimodais que congregam linguagem verbal e visual técnica. Com base nos sistemas de Avaliatividade verbal (Martin \& White, 2005) e visual (Economou, 2009), analisamos 14 textos que divulgam pesquisas de opinião pública. Os resultados revelam que a estrutura das pesquisas é perpassada pelo fechamento dialógico e pelo direcionamento da manifestação avaliativa. Imagens técnicas apresentam a gradação (principalmente de força) como sinal avaliativo inerente. $O$ engajamento é marca recorrentemente inscrita, via seleção de cores, inserção de dados intertextuais, destaques, comparações de dados e arranjo do texto. Os posicionamentos avaliativos evocados são condicionados ao contexto de recepção (nível de leitura,

1. O presente trabalho foi realizado com apoio da Coordenação de Aperfeiçoamento de Pessoal de Nível Superior - Brasil (CAPES) - Código de Financiamento 001.

2. Universidade Federal de Santa Maria. Rio Grande do Sul - Brasil. https://orcid.org/00000003-4797-3283. E-mail: crisflorek@hotmail.com.

3. Universidade Federal de Santa Maria. Rio Grande do Sul - Brasil. https://orcid.org/00000002-0303-0737. E-mail: sara.scotta.cabral@gmail.com. 
percepção do assunto, p. ex.) e às conduções interpretativas inscritas pela equipe editorial. Sendo assim, da coleta à divulgação, a opinião pública é sutilmente construída, e a Avaliatividade tem papel essencial nesse processo.

Palavras-chave: Avaliatividade; Multimodalidade; Opinião pública; Textos de divulgação.

\begin{abstract}
We aim to investigate evaluative positions in multimodal texts that bring together verbal and technical visual language. Based on Appraisal systems of verbal (Martin \& White, 2005) and visual (Economou, 2009), we analyzed 14 texts that disseminate public opinion. The results reveal that survey structure is permeated by the dialogical closure and targeting of evaluative manifestation. Technical images present gradation (mainly of force) as an inherent evaluative signal. Engagement is repeatedly inscribed, through color selection, insertion of intertextual data, highlights, data comparisons and text arrangement. The evaluative positions evoked are conditioned to the context of reception (level of reading, perception of the subject, e.g.) and to the interpretative guidelines registered by the editorial team. Thus, from gathering to release, public opinion is subtly constructed, and Appraisal plays an essential role in this process.
\end{abstract}

Keywords: Appraisal; Multimodality; Public opinion.

\title{
Introdução
}

"A linguagem entrega". Não raramente, essa assertiva é mobilizada com propósito comprobatório em situações de disputa argumentativa ou quando leitores/ouvintes/espectadores estão empenhados na interpretação crítica de uma informação recebida. No entanto, essa afirmação "xeque-mate" dificilmente ocorre junto à exposição dos elementos linguísticos que "entregam" e do que é efetivamente entregue.

Nos mais variados contextos, existe, inclusive, um esforço para o apagamento de manifestações de caráter subjetivo e/ou persuasivo (Florek, 2018). Contextos e práticas sociais, inerentemente subjetivos, como é o caso das sondagens de opinião pública, investem-se de neutralidade e de objetividade almejando externalizar indicadores fidedignos 
da opinião popular (Bourdieu, 1973). Para tanto, empregam recursos como a exposição de dados estatísticos e a representação dos índices de opinião pública por meio de imagens técnicas.

A opinião pública, contudo, é compreendida como um instrumento de ação política entre os estudiosos do tema, pelo qual se procura "constituir a ideia de que existe uma opinião pública unânime" (Bourdieu, 1973, p. 3). Assim, ao lado da tradição (educação familiar, aprendizagem profissional e ensino escolar) e da razão (observação, experiência e pesquisa, ou, raciocínio e dedução baseada em textos), a opinião pública (conjunto de juízos ou desejos) seria uma força que contribui para definir com parcialidade o valor das coisas, pois "a opinião gosta de tomar partido em suas disputas” (Tarde, 2005, p. 61).

No processo de instrumentalização da opinião pública, existe, ainda, a opinião pública publicada, que abrange compilações informativas transformadas em "insumos para o pensar, o dizer, o discutir, o conversar, em parâmetro para orientação das decisões e em disposições no campo cultural, econômico, político" (Gomes, 2001, p. 8, grifos do autor). Assim, a opinião pública publicada revelaria juízos, alinhamentos, percepções de mundo e relações de poder que envolvem diferentes grupos, como as empresas de sondagem, os contratantes da pesquisa e a equipe editorial.

No campo da investigação linguística de perspectiva sistêmico-funcional (Halliday \& Matthiessen, 2014), especificamente no que tange às trocas interpessoais, existem estudos que permitem demonstrar como significados do sistema semântico-discursivo são revelados via fraseados (léxico-gramática) (Martin \& White, 2005). Entretanto, considerando que a linguagem pode "entregar" em diferentes modos, dependendo dos sistemas semióticos acionados para produzir sentido, os mecanismos de análise existentes ainda são restritos.

Sendo assim, neste estudo, objetivamos observar, descrever e discutir textos multimodais que divulgam pesquisas de opinião pública. Para tanto, respaldamo-nos na literatura prévia sobre marcas avaliativas em linguagem verbal (Martin \& White, 2005) e em imagens realísticas da mídia (Economou, 2009). Com isso, pretendemos avançar as fronteiras do conhecimento, sobretudo no que concerne ao estudo da Avaliatividade em textos que congregam linguagem verbal escrita e visual técnica (diagramas, gráficos, tabelas, p. ex.). 
Este artigo apresenta cinco seções. A seguir, sumarizamos os sistemas de Avaliatividade verbal e visual. Na sequência, detalhamos o universo de análise, o corpus e as categorias analíticas da pesquisa. Na quarta seção, descrevemos e discutimos os resultados encontrados. Por fim, propomos algumas considerações gerais sobre a Avaliatividade em textos multimodais de caráter técnico.

\section{Revisão da Literatura}

No âmbito dos estudos sistêmico-funcionais (Halliaday \& Matthiessen, 2014), Martin e White (2005) propuseram o sistema de Avaliatividade, uma categorização de recursos interpessoais disponíveis no estrato semântico-discursivo ${ }^{4}$ para expressar opiniões e externalizar posicionamentos subjetivos. Esse sistema se realiza pelos subsistemas de atitude, engajamento e gradação, que possibilitam perceber avaliações feitas especialmente em instanciações verbais (orais ou escritas).

A Figura 1 representa as lentes de análise possibilitadas pela Linguística Sistêmico-Funcional e o espaço ocupado pelo sistema de Avaliatividade.

Figura 1 - Sistema de Avaliatividade e lentes de análise da linguagem

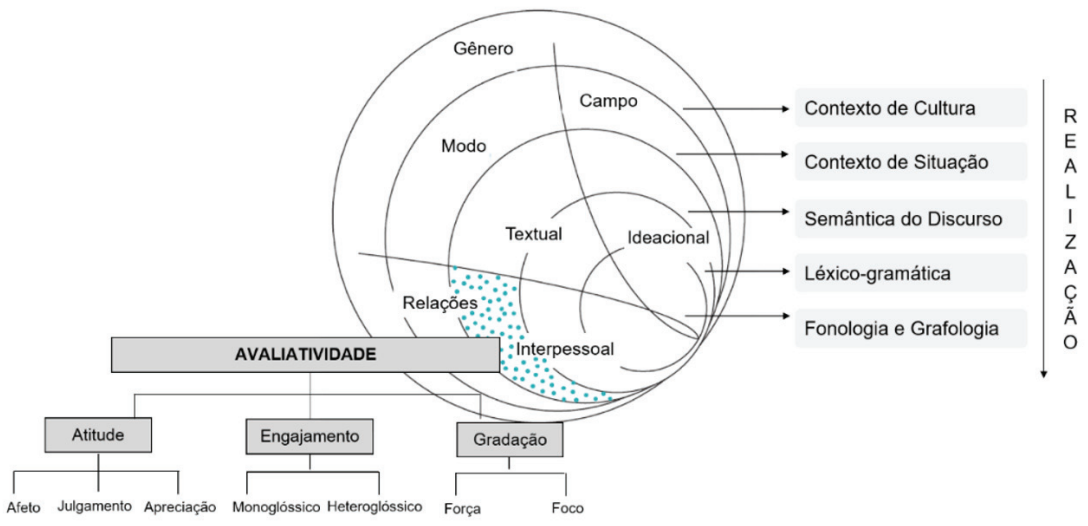

Fonte: elaborada pelas autoras.

4. No estrato semântico-discursivo, existem mais dois recursos: a Negociação, que trata das funções de fala, e o Envolvimento, que trata da solidariedade entre interlocutores (Martin \& White, 2005, p. 33-38). 
Seguindo os pressupostos de Martin e White (2005), Economou (2009) investigou imagens realísticas em notícias da imprensa, pontuando que a semiótica visual, assim como a verbal, dispõe de recursos para a construção de relações entre a foto e o leitor pelo modo como normas e valores da equipe de produção ou dos leitores putativos "se intrometem" na dimensão experiencial da foto. A seguir, revisaremos os três subsistemas do sistema de Avaliatividade, considerando a linguagem verbal e a linguagem visual.

\section{Subsistema de atitude}

O subsistema de atitude pode ter manifestações implícitas e explícitas (Martin \& White, 2005). Manifestações implícitas evocam uma interpretação do ouvinte/leitor e são realizadas por significados ideacionais que envolvem menções sutis ou linguagem figurada. Manifestações explícitas ocorrem quando uma avaliação positiva ou negativa é inscrita no discurso, podendo ser intensificada para mais ou para menos.

Conforme Economou (2009), em imagens, a atitude explícita ocorre quando há uma representação visual da atitude inscrita. A atitude implícita varia em um gradiente quanto ao nível de dependência do contexto e de liberdade de interpretação (Economou, 2009, p. 108) e pode ser: i) provocada: pelo emprego de metáfora ideacional visual; ou ii) solicitada: pela gradação visual ou por símbolos visuais ideacionais.

Nos subsistemas de atitude verbal e visual, podem ocorrer avaliações de afeto, julgamento ou apreciação.

\section{Afeto}

Avaliações de afeto expressam sentimentos positivos ou negativos, cuja autoria é atribuída ao falante ou escritor, exceto em caso de projeção (locução ou relato). O afeto reflete emoções de: i) in/felicidade: relacionadas ao coração, ao gostar ou não gostar (tristeza, felicidade, ódio e amor); ii) in/segurança: concernentes ao bem-estar social (ansiedade, temor, confiança em relação ao ambiente e às pessoas); ou iii) in/satisfação: referentes ao sentimento de alcance dos objetivos ou de frustração (tédio, desprazer, curiosidade, respeito). 
Visualmente, os valores de afeto são os mesmos da linguagem verbal e podem ser inscritos ou evocados. Quando o afeto é inscrito, a representação conta com um Gatilho (Trigger) e um Afetado (Emoter). Em alguns casos, o Gatilho não está representado, mas o olhar do Afetado indica sua existência. No caso do Afeto evocado, as representações provocam emoções no espectador pela projeção dos leitores putativos e dos sistemas de sentimentos existentes na sociedade. Assim, a representação é o Gatilho, e o leitor o Afetado.

\section{Julgamento}

O julgamento institucionaliza sentimentos, expressando avaliações moldadas de acordo com uma cultura particular e as crenças de determinados grupos sociais. O julgamento viabiliza avaliar o comportamento das pessoas quanto a: i) estima social: avaliações de admiração ou crítica sem implicações legais, que permitem julgar o comportamento em termos de normalidade (o quão especial, comum ou incomum alguém é), capacidade (o quão capaz, competente alguém é) e tenacidade (o quão confiável alguém é); e ii) sanção social: avaliações de elogio e de condenação, geralmente com complicações legais, que permitem avaliar a propriedade (o quão honesto, confiável alguém é) e a veracidade (o quão ético alguém é) do comportamento, de acordo com as determinações de instituições com poder de punição (igreja e Estado, p. ex.).

No sistema visual, assim como no verbal, o julgamento pode suscitar avaliações de estima e de sanção social e pode ser inscrito ou evocado. O julgamento enfrenta mais restrições de inscrição em comparação ao afeto, mas quando inscrito, geralmente, está associado à representação de feições ou gestos humanos icônicos, comumente reconhecíveis como julgamento (aplausos, um sinal de vitória, p. ex.). Quem efetiva o julgamento é denominado Avaliador e a pessoa/ comportamento julgado é denominado Alvo, que pode ou não estar representado.

O julgamento não inscrito está geralmente embutido em um processo material representado. Assim, uma mãe acarinhando o filho tende a evocar no Avaliador um julgamento de sanção social (propriedade: 
a mãe é confiável). Contudo, alguns valores são menos universais e mais dependentes do contexto. Representações humanas que não estão envolvidas em um processo material podem evocar julgamentos devido a atributos como força corporal ou habilidades físicas (capacidade e/ ou normalidade). Em outros casos, o participante representado pode ser reconhecido como um ator social individual (uma pessoa famosa, p. ex.) ou como símbolo de um grupo social, evocando julgamentos com base no que se pondera ser o comportamento típico daquela pessoa ou grupo.

Além disso, imagens em que não há participante humano ou comportamento representado podem evocar valores de julgamento, desde que os efeitos impliquem agência humana. Metáforas ideacionais visuais, comuns em caricaturas ou cartoons, ou "produzidas" via edição e seleção de fotografias e combinação de textos verbais, também são propícias à evocação de julgamentos ${ }^{5}$. O julgamento pode ter ocorrência simultânea com o afeto, adicionando complexidade e força às respostas atitudinais evocadas, ainda que a evocação do afeto no leitor possa ser complicada pelo nível de identificação que ele tenha com o(s) ator(es) social(is) representado(s).

\section{Apreciação}

O subsistema de apreciação abrange avaliações estéticas de fenômenos semióticos (como textos) e naturais (objetos), de acordo com os padrões de avaliação reconhecidos e naturalizados em cada campo; trata-se da avaliação das coisas (Martin \& White, 2005). Os significados avaliativos de apreciação podem ser de: i) reação: indicam o impacto ou a qualidade de determinada coisa, objeto; ii) composição: fazem referência à proporção e complexidade das coisas, objetos; e iii) valor: indicam a relevância ou originalidade das coisas, objetos.

Visualmente, não é possível inscrever a apreciação em uma imagem. Assim, os espectadores agem como Apreciadores, tendo como

5. Para um exemplo, consulte Florek (2017, p. 217), foto de Dilma Rousseff. Outro exemplo é a fotografia presente na matéria publicada no Estadão online de 23 de janeiro de 2020; para consulta: https://politica.estadao.com.br/noticias/geral,bolsonaro-diz-que-ja-estuda-possivel-recriacao-do-ministerio-da-seguranca-publica,70003169583 
Apreciado aquilo que está representado visualmente. O Apreciado pode ser tanto a imagem como um todo quanto elementos ou partes de elementos representados. A imagem como um artefato semiótico pode evocar apreciações simultâneas: ao afetar emocionalmente os espectadores, evoca uma apreciação de reação; a depender do foco institucional dado no intuito de informar os espectadores sobre eventos recentes, evoca uma apreciação de valoração (valor de notícia: potencial desestabilizador ou reestabilizador em relação aos leitores putativos); e pelo prazer visual que pode causar, suscita uma apreciação de composição ${ }^{6}$.

A reação tem relação estreita com o afeto e o julgamento, pois muitas fotos, especialmente as de capa ou de destaque, são deliberadamente selecionadas com o objetivo de causar uma reação emocional ou evocar atitudes de afeto e/ou julgamento. No caso da apreciação de composição, alguns recursos do sistema visual (o enquadramento e a perspectiva) são recrutados para que haja um deslocamento da imagem como artefato de informação para artefato artístico, exacerbando o aspecto autoral e subjetivo da imagem.

A apreciação pode incidir sobre itens visuais específicos: i) participante humano: o Apreciado é o corpo do participante (forma, disposição dos atributos; partes específicas, roupas e acessórios); ii) participante não humano: o Apreciado são objetos representados e que não estejam envolvidos em uma ação (simples, interessante, bonito, feio); iii) comportamento humano representado: além do valor de julgamento evocado por um comportamento representado, a postura e movimento capturados por uma foto também podem ser apreciados como "coisas" em termos de composição (movimento simétrico, gracioso), valor (único, impossível) e reação (impressionante).

Na Figura 2, apresentamos o subsistema de atitude em imagens realísticas da mídia, conforme Economou (2009).

6. A foto veiculada na capa de um jornal gaúcho no dia seguinte à tragédia ocorrida na boate Kiss evoca simultaneamente os três tipos de apreciação. Veja Florek (2017, p. 219). 
Figura 2 - Subsistema de atitude em imagens realísticas da mídia

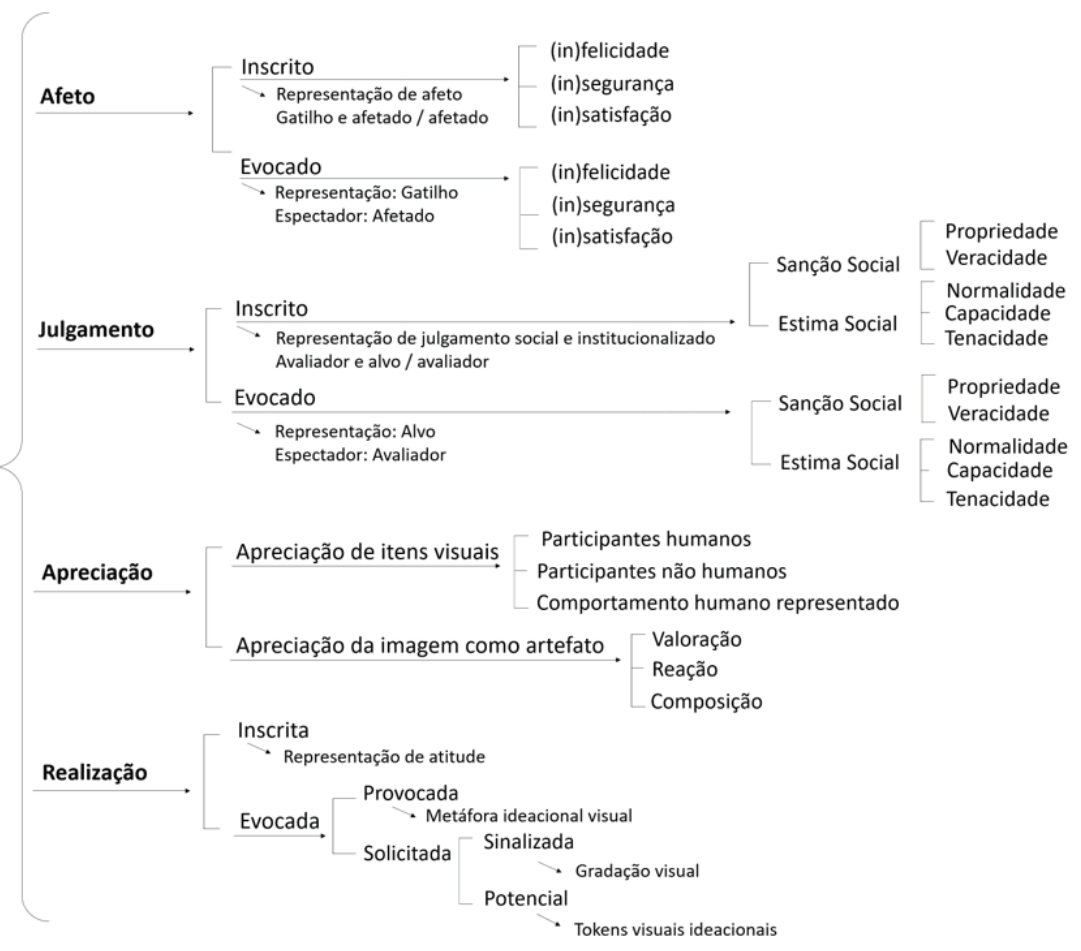

Fonte: elaborada pelas autoras.

\section{Subsistema de engajamento}

O subsistema de engajamento viabiliza investigar os efeitos retóricos associados à tomada de posição em um texto: como o autor compromete-se ou exime-se em relação à mensagem expressa ou polariza as informações veiculadas.

O engajamento pode indicar: i) atitude monoglóssica: o produtor do texto enuncia algo presumível, que está pressuposto, ou assertivo, que não admite interação dialógica (Ninin \& Barbara, 2013); ii) ou atitude heteroglóssica: o autor reconhece a diversidade de fontes, recrutando-as na tessitura do texto (expansão dialógica) ou desencorajando a negociação de sentidos (contração dialógica).

Em imagens realísticas, salvaguardadas as limitações técnicas, a imagem monoglóssica terá o objetivo de ser uma substituta do olho 
humano, sendo considerada não marcada, sem interferência subjetiva (escolhas de enquadramento, perspectiva, foco, luz, p. ex.). Cabe, entretanto, mencionar que, pela seleção das fotos, dos fatos e do ângulo factual, imagens sem inscrição de atitude ou sem citações incorporadas podem atuar como símbolos de valores atitudinais, sugestionando uma resposta atitudinal nos espectadores.

No caso da heteroglossia visual, existe apenas expansão dialógica, cujos recursos, assim como na linguagem verbal, materializam-se por extravocalização (atribuição) ou intravocalização (entretenimento).

A atribuição ocorre em imagens não marcadas e pode ser incorporada ou substitutiva. Quando incorporada, ao modo da projeção em linguagem verbal, a atribuição efetiva-se pela inscrição da voz de outrem via representação de valores de atitude (aplauso, sinal de "positivo", p. ex.) ou anexação de uma citação visual, que pode ser verbal escrita (cartaz, placa) ou visual (um desenho ou foto dentro da foto).

A atribuição substitutiva acontece quando algum texto externo, muitas vezes originalmente visual, como uma pintura ou desenho, atua como a foto da notícia (Economou, 2009, p. 208). Exemplo recente foi a foto de capa de um jornal brasileiro após ordem de recolhimento de um livro na Bienal do Rio, caso em que a imagem do livro que motivou o ato de censura tornou-se foto da matéria ${ }^{7}$.

Ainda que a premissa seja de que as fotos de notícia objetivam representar a fatualidade, recorrentemente encontramos imagens que sinalizam a subjetividade autoral. Conforme Economou (2009), isso é considerado heteroglossia intravocalizada, pois coloca a voz textual interna em primeiro plano. Esse movimento expande o espaço dialógico, posicionando a voz interna como uma entre várias posições, o que equivale ao entretenimento. No modo semiótico visual, o entretenimento se realiza: i) pela expressão marcada: seleção a níveis extremos dos recursos interativos e de modalidade (perspectiva, enquadramento, tomada de câmera, luz, foco, cor, conf. Kress \& Van Leeuwen, 2006), a fim de tornar as representações visuais menos congruentes e o sentido menos naturalista; ou ii) pela ideação marcada, seleção representacional 
atípica ou não representativa do assunto no contexto jornalístico ${ }^{8}$. O engajamento por entretenimento também pode se expressar quando manchete e imagem geram uma aparente incongruência ou atipicidade.

Na Figura 3, apresentamos o subsistema de engajamento visual.

Figura 3 - Subsistema de engajamento em imagens realísticas da mídia

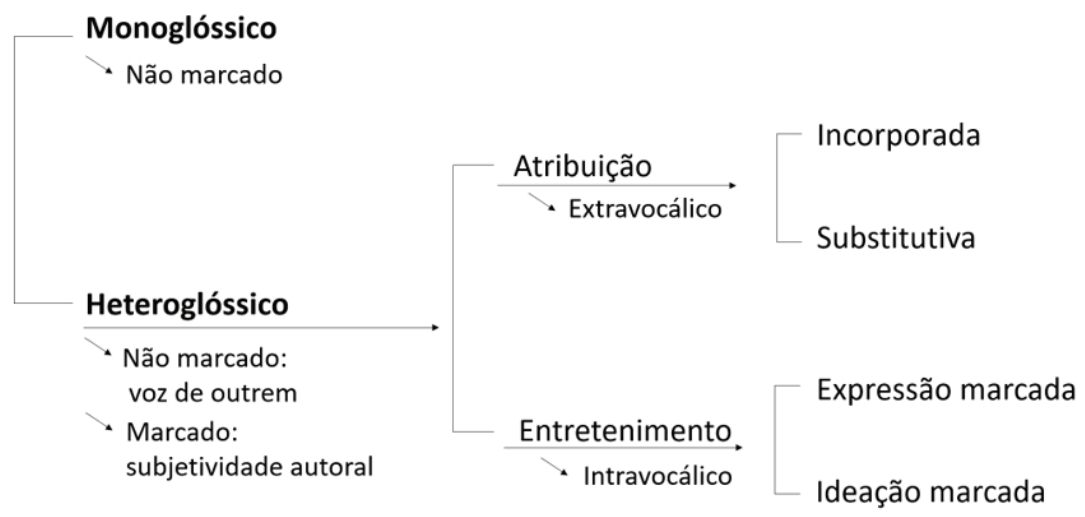

Fonte: Adaptado de Economou, D. (2009). Photos in the news: appraisal analysis of visual semiosis and visual-verbal intersemiosis (p. 209). [PhD thesis, University of Sydney]: Sydney Digital Theses. http://hdl.handle.net/2123/5740

\section{Subsistema de gradação}

O subsistema de gradação baseia-se em acepções sociais sobre uma escala virtual de intensidade que se orienta de um polo de avaliações menos intensas a outro de avaliações apresentadas como mais intensas. Martin e White (2005) apresentam duas possibilidades de escala: i) força: intensificação de qualidades e/ou processos ou quantificação de entidades quanto à quantidade, volume e extensão; e ii) foco: classificação da prototipicidade, acentuando ou atenuando o grau em que uma entidade, que em princípio não aceitaria ser graduada, aproxima-se de uma determinada categoria semântica (ele é quase um pai; isso é praticamente uma cama, p. ex.).

8. Para um exemplo de ideação marcada: https://istoe.com.br/e-evidente-que-esse-homem-esta-doente/ 
Conforme Economou (2009), o sistema de gradação visual usa formas de expressão espacial e tessitural para dimensionar para cima ou para baixo significados visuais representacionais, sinalizando, assim, uma leitura avaliativa desses significados. A expressão espacial organiza formas visuais no espaço visual, principalmente por meio dos ângulos da câmera e enquadramento. A expressão tessitural oferece qualidade a formas visuais e ao espaço, principalmente pela seleção de luz, cor e foco da câmera.

Visualmente, a gradação opera escalas de força e de foco, assim como ocorre na linguagem verbal. A força se realiza por: i) quantificação; ii) repetição; e iii) intensificação.

A quantificação (aumento ou diminuição) é realizada pela expressão espacial e se refere: i) ao número de um elemento, sem que se dê destaque à individualidade (muitos, poucos corredores em uma maratona, p. ex.); ii) à massa/montante de um elemento (pequeno, grande); e iii) à extensão de um elemento, em termos de proximidade (item perto ou longe do espectador) e de distribuição (item ocupa mais ou menos espaço na imagem: o local exato da colisão entre um caminhão e um carro toma o espaço da foto).

A repetição (dois ou mais itens semelhantes na imagem), realizada pela expressão espacial, refere-se à multiplicação de itens semelhantes, mas não de um grupo grande, de modo que cada item seja individualmente distinto e capaz de evocar algum valor de atitude por si só, geralmente, em termos de algum atributo claro.

A intensificação (mais ou menos brilhante) se realiza pela expressão tessitural de luminosidade (intensidade da cor) e de vivacidade (cor e saturação). Assim, um elemento pode ganhar força para mais ou para menos.

A gradação visual pelo foco se dá unicamente pela especificação, que se realiza: i) pela claridade, via foco da câmera (tessitural) e enquadramento interno (espacial), possibilitando distinguir um item dos demais pela quantidade de detalhes visíveis da superfície ou do contorno; ii) pela conclusão (espacial), via ângulos e valor de crop (corte), que revelam quantas partes do item são visíveis; e iii) pela 
substanciação, via variação da luz, exposição e velocidade, que tem relação com a profundidade visível ou dimensionalidade de um item.

Na Figura 4, exibimos o sistema de gradação visual.

Figura 4 - Subsistema de gradação em imagens realísticas da mídia

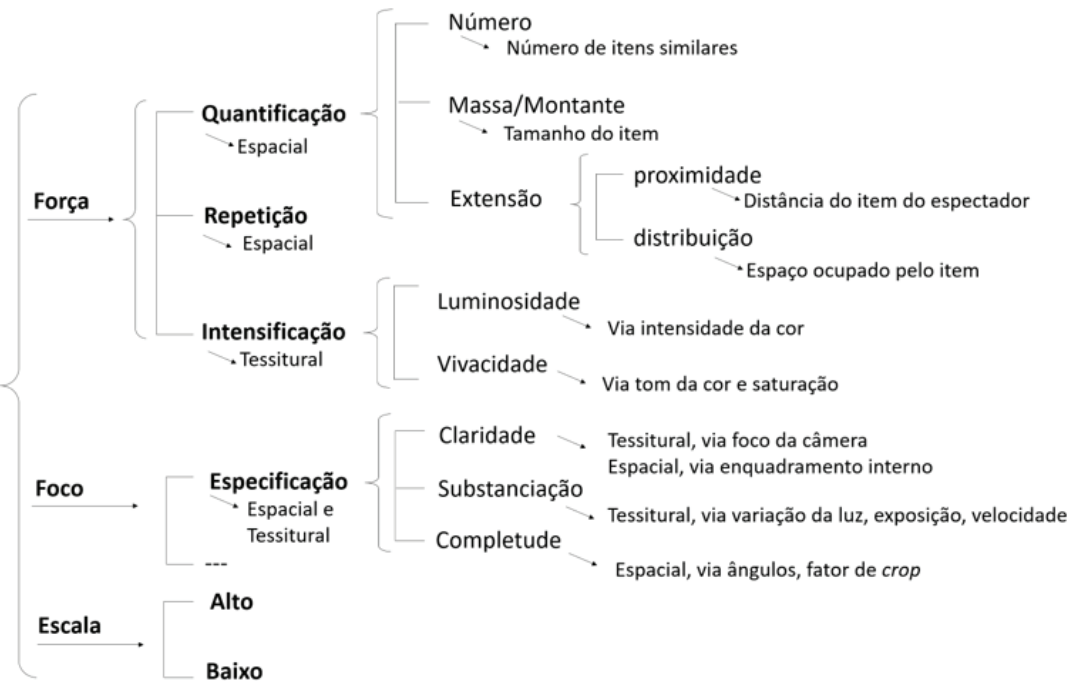

Fonte: Adaptado de Economou, D. (2009). Photos in the news: appraisal analysis of visual semiosis and visual-verbal intersemiosis (p. 163). [PhD thesis, University of Sydney]: Sydney Digital Theses. http://hdl.handle.net/2123/5740

Na próxima seção, apresentamos o desenho metodológico desta pesquisa.

\section{Metodologia}

O IBOPE-Inteligência (anteriormente denominado IBOPE - Instituto Brasileiro de Opinião Pública e Estatística) é uma das maiores e mais populares empresas de pesquisa de mercado da América Latina (Ibope-Inteligência, 2020). Em uma varredura na página online do IBOPE-Inteligência ${ }^{9}$, encontramos um gênero multimodal que é de

9. Para acessar o site: https://www.ibopeinteligencia.com/. 
nosso interesse investigativo: o texto de divulgação de pesquisa de opinião pública.

Geralmente, as pesquisas de opinião pública realizadas pelo IBOPE-Inteligência são encomendadas por um contratante, cuja identidade consta na ficha técnica apresentada ao final do texto de divulgação. Um dos maiores contratantes de pesquisas junto ao IBOPE é a Confederação Nacional da Indústria (CNI), entidade representativa da cúpula do empresariado brasileiro.

Para realizar a seleção de nosso corpus de pesquisa, primeiramente acessamos a página do IBOPE-Inteligência, em seguida a aba Notícias e Pesquisas e, então, selecionamos a opção CNI. Decidimos estabelecer nosso período de coleta entre fevereiro de 2019 e fevereiro de 2020. Para o ano de 2019, encontramos 13 pesquisas, realizadas entre fevereiro e dezembro; e para o ano de 2020, até o mês de fevereiro, encontramos somente uma pesquisa.

Sendo assim, nosso corpus compreende 14 textos de divulgação de pesquisas de opinião contratadas pela CNI, coletadas no site IBOPE-Inteligência, totalizando 45 imagens, sendo quatro imagens realísticas (fotografias) e 41 imagens técnicas (gráficos, tabelas, p. ex.), conforme Tabela 1.

Tabela 1 - Tabulação de informações sobre o corpus de análise

\begin{tabular}{|c|c|c|c|c|}
\hline \multicolumn{5}{|c|}{$\begin{array}{l}\text { IBOPE Inteligência - Notícias e Pesquisas - CNI } \\
\text { fevereiro } 2019 \text { - fevereiro } 2020\end{array}$} \\
\hline \multirow{2}{*}{$\begin{array}{c}\text { Texto } \\
\text { de } \\
\text { divulgação }\end{array}$} & \multirow{2}{*}{ Data } & \multirow{2}{*}{ Título da Pesquisa } & \multicolumn{2}{|c|}{ Texto visual } \\
\hline & & & Real. & Técn. \\
\hline$\# 1$ & 08.02 .19 & $\begin{array}{l}\text { Medo de desemprego tem maior queda da série } \\
\text { histórica }\end{array}$ & 0 & 2 \\
\hline$\# 2$ & 24.04 .19 & $\begin{array}{l}\text { Avaliação positiva de Jair Bolsonaro permanece } \\
\text { estável em abril; avaliação negativa continua em } \\
\text { tendência de crescimento }\end{array}$ & 1 & 5 \\
\hline$\# 3$ & 09.05.19 & $\begin{array}{l}\text { Cai a confiança do consumidor na primeira leitura } \\
\text { do ano }\end{array}$ & 0 & 1 \\
\hline$\# 4$ & 09.05 .19 & $\begin{array}{l}\text { Medo de desemprego aumenta em relação a } \\
\text { dezembro }\end{array}$ & 0 & 1 \\
\hline$\# 5$ & 28.06 .19 & $\begin{array}{c}\text { Avaliação negativa de Bolsonaro aumenta; confiança } \\
\text { no presidente diminui }\end{array}$ & 0 & 5 \\
\hline
\end{tabular}




\begin{tabular}{|c|c|c|c|c|}
\hline$\# 6$ & 02.07 .19 & Confiança do consumidor cai novamente & 1 & 1 \\
\hline$\# 7$ & 05.07 .19 & Medo de desemprego aumenta entre abril e junho & 0 & 1 \\
\hline$\# 8$ & 13.08 .19 & Para 60\% da população, reforma da Previdência é \\
necessária & 0 & 1 \\
\hline$\# 9$ & 27.09 .19 & $\begin{array}{c}\text { Popularidade de Bolsonaro mantém-se praticamente } \\
\text { estável }\end{array}$ & 0 & 4 \\
\hline$\# 10$ & 27.09 .19 & Confiança do consumidor fica praticamente estável & 1 & 0 \\
\hline$\# 11$ & 18.12 .19 & $\begin{array}{c}\text { Metade da população acredita em melhora na } \\
\text { economia em 2020 }\end{array}$ & 0 & 3 \\
\hline$\# 12$ & 20.12 .19 & Confiança do consumidor segue estável & 0 & 1 \\
\hline$\# 13$ & 20.12 .19 & $\begin{array}{c}38 \% \text { consideram administração de Bolsonaro ruim } \\
\text { ou péssima }\end{array}$ & 0 & 4 \\
\hline$\# 14$ & 18.02 .20 & Principais problemas do país e prioridades para 2020 & 1 & 12 \\
\hline & TOTAL & $\mathbf{4}$ & $\mathbf{4 1}$ \\
\cline { 3 - 6 } & & 4 & $\mathbf{4 5}$ \\
\hline
\end{tabular}

Para a investigação do corpus, ativemo-nos aos elementos visuais (tabelas, gráficos, fotos, digramas) e a elementos verbais diretamente atrelados a eles (manchetes e legendas, p. ex.). As categorias de análise advêm do estudo de Economou (2009) sobre o sistema de Avaliatividade de imagens realísticas da mídia, conforme sintetizado nas Figuras 2, 3 e 4. Além disso, quando necessário, lançamos mão do estudo de Martin e White (2005) sobre o sistema de Avaliatividade em linguagem verbal escrita.

\section{Resultados e Discussão}

A parceria IBOPE-Inteligência e CNI, iniciada em 1996, gera publicações oficiais das pesquisas completas e, também, textos de divulgação que tendem a ser recebidos como a expressão da opinião de todo(a)s o(a)s brasileiro(a)s indistintamente, servindo como referência para a tomada de decisões políticas e econômicas. Isso pode advir da forte institucionalização que cerca a parceria, com a realização de quatro rodadas de pesquisa nacional (março, junho, setembro e dezembro) e de pesquisas estratégicas específicas, que subsidiam índices importantes para o empresariado e governo brasileiros (CNI-IBOPE, 2010).

As pesquisas de opinião pública analisadas neste estudo podem ser dividias em seis grupos: três deles englobam rodadas de pesquisa 
replicadas de forma idêntica ao longo do ano; os outros três apresentam pesquisas individuais de interesse público:

Grupo 1) Medo do desemprego e satisfação com a vida (\#1; \#4 e \#7);

Grupo 2) Percepções sobre o governo (\#2; \#5; \#9 e \#13);

Grupo 3) Confiança do consumidor (\#3; \#6; \#10 e \#12);

Grupo 4) Reforma da previdência (\#8);

Grupo 5) Perspectivas para a economia em 2020 (\#11);

Grupo 6) Problemas e prioridades do país para 2020 (\#14).

A seguir, discutimos o modo como as pesquisas são organizadas e o teor das perguntas realizadas.

\section{A pesquisa de opinião pública}

O texto de divulgação de pesquisa de opinião pública sintetiza um amplo processo de pesquisa de campo, tabulação de respostas, fiscalização e processamento dos dados e execução de relatório detalhado (CNI, 2010). Nesta pesquisa, nosso foco é o texto síntese que serve como meio de divulgação da pesquisa e pode ser consultado na página online do IBOPE-Inteligência. Entretanto, a fim de compreender o contexto de nosso objeto de estudo, recorremos algumas vezes à leitura do relatório completo de cada pesquisa, disponibilizado para download em uma entrada ao final dos textos de divulgação.

Desse modo, observamos que o texto de divulgação tende a assemelhar e condensar resultados que, conforme indica o relatório completo, advêm do cruzamento de uma série de variáveis relacionadas ao perfil do(a)s entrevistados(a)s (região do Brasil em que habita; porte do município em que habita; renda familiar; sexo; idade; escolaridade). Assim, ao que parece, o texto de divulgação orienta-se pela homogeneização das respostas, o que em termos de representação transforma a diversidade do(a)s brasileiro(a)s, considerada no ato da pesquisa, em um padrão único no ato da divulgação geral dos resultados. Isso revela parte do processo de construção da opinião pública publicada, endossando a perspectiva de Gomes (2001) sobre o aparelhamento da opinião pública, especialmente na fase de publicação. 
Eventualmente, no texto de divulgação, as respostas são apresentadas diferenciando características do perfil do(a)s entrevistado(a)s, mas sem um critério claro, conduzindo à interpretação de que se trata de engajamento editorial. Ainda que esse recorte na apresentação dos resultados intente arejar ou facilitar a compreensão da pesquisa, os dados completos aparecem timidamente como um hiperlink para download, podendo ser desconsiderados pelo leitor, que consumirá somente os dados apresentados no texto de divulgação, podendo entendê-los, portanto, como os únicos dados da pesquisa.

Quanto às perguntas realizadas, $86,0 \%$ das 43 questões mapeadas ${ }^{10}$ apresentam conteúdo avaliativo no enunciado, nas alternativas ou em ambos. Destas, 76,7\% solicitam ou apresentam engajamento; $69,7 \%$ apresentam opções de resposta que requerem do entrevistado uma gradação (de força em todos os casos); e 23,2\% demandam uma atitude (afeto, julgamento ou apreciação) como resposta ${ }^{11}$.

As duas perguntas que compõem a pesquisa sobre Medo do desemprego e satisfação com a vida (Grupo 1) demandam do respondente uma atitude de afeto e uma gradação dessa atitude em relação aos temas abordados, conforme exemplo a seguir:

P2 - Com relação ao desemprego, pensando no(a) sr(a) e nas pessoas de sua família, o(a) sr(a) diria que:

Está com muito medo de ser afetado pelo desemprego / Está com um pouco de medo de ser afetado pelo desemprego / Não está com medo de ser afetado pelo desemprego / Já está desempregado/Já foi afetado / Não sabe/ Não respondeu.

A resposta não pode ser considerada uma externalização espontânea de um sentimento do respondente, pois as alternativas fecham o espaço dialógico ao se limitarem a um sentimento (medo, no caso do exemplo) e possíveis gradações que o polarizaram (tem / não tem). Não

10. Questões que se repetem devido à replicação da pesquisa ao longo do ano foram contabilizadas uma única vez. Questões que possuem o mesmo cabeçalho e as mesmas opções de resposta, mas se subdividem por conta de avaliarem diferentes variáveis, também foram contabilizadas uma única vez (p. ex., questão 1A demanda opinião sobre taxa de juros, 1B sobre desemprego, 1C sobre educação...).

11. A soma dos percentuais excede $100 \%$ em virtude de algumas perguntas apresentarem mais de uma categoria avaliativa. 
há margem para a expressão de outra percepção. A opção de resposta não sabe/não respondeu pode ser compreendida como uma escolha para aqueles que não apoiam o que foi presumido nas alternativas ou indicado no enunciado.

As oito perguntas que compõem o Grupo 2, Percepções sobre o governo, requerem apreciações sobre o governo do presidente Jair Bolsonaro, o restante do mandato, o atual mandato em comparação com o governo anterior e sobre as notícias concernentes ao governo veiculadas na mídia; julgamentos sobre o modo de governar e a confiabilidade do presidente; engajamento em relação à atuação do presidente em questões específicas; e gradação de todos os posicionamentos. Vejamos um exemplo:

P1 - Na sua avaliação, o governo do presidente Jair Bolsonaro está sendo: Ótimo / Bom / Regular / Ruim / Péssimo / Não sabe/Não Respondeu

P6 - Para cada um dos assuntos citados, gostaria que o(a) sr(a) dissesse se aprova ou desaprova a atuação do Governo o presidente Jair Bolsonaro até o momento.

Aprova / Desaprova / Não sabe/Não respondeu

Nesse conjunto de perguntas, existe uma alternância de percepção sobre o governo como um fenômeno, passível de apreciação, e como algo centrado na figura e atuação do presidente, passível de julgamento.

Sobre a sondagem quanto à Confiança do consumidor (\#3; \#6; \#10 e \#12) apresentamos dois exemplos:

$\mathbf{P 2}$ - Levando em conta a situação do país nos últimos seis meses, na sua opinião, nos próximos seis meses a inflação:

Vai aumentar muito / Vai aumentar / Vai diminuir / Vai diminuir muito / Não sabe/Não respondeu

P4 - O(a) sr(a) diria que em relação aos últimos três meses está:

Muito mais endividado / Mesmo número de dívidas dos últimos três meses / Menos endividado / Muito menos endividado / Não tem dívidas / Não sabe/não respondeu

Destacamos a presença de estratégias de engajamento no enunciado de quatro das cinco questões desse grupo. Em algumas delas, o recurso de engajamento fecha o espaço dialógico, pois sugestiona a 
existência de uma premissa (endividamento, necessidade de compra de bens domésticos de maior valor). Em outras perguntas, a aparente abertura do espaço dialógico pelo emprego de na sua opinião acaba não se concretizando diante das restrições impostas pelas alternativas. Além disso, assim como em questões de outros grupos, as alternativas de resposta sugerem que o respondente indique o grau da sua apreciação, quando for o caso, ou forneça avaliações de gradação quanto às premissas expostas nas questões.

No conjunto de 19 questões sobre a Reforma da previdência (\#8), a sequência das perguntas sugere um aprofundamento gradual do conteúdo abordado, sempre com respaldo em recursos de engajamento.

P1 - De forma geral, pensando no que o(a) sr(a) sabe ou ouviu falar até o momento, o(a) sr(a) concorda ou discorda que é preciso reformar a previdência?

Concorda totalmente / Concorda em parte / Não concorda nem discorda / Discorda em parte / Discorda totalmente / Não sabe/Não respondeu

Inicialmente, informa-se, assertivamente, que é preciso reformar a previdência, mas se indica que aquilo que o respondente sabe ou ouviu falar sobre o assunto pode auxiliá-lo a indicar sua anuência ou não a essa necessidade. Novamente, sem espaço para negociação, informa-se que há uma proposta de reforma da previdência e se demanda a anuência ou não do inquirido (aprova/desaprova). Perguntas pontuais sobre aspectos da reforma da previdência, por exemplo, a idade com que uma pessoa deve se aposentar, sugerem que o respondente deve se basear na própria opinião, mas as opções de resposta limitam essa opinião, oferecendo alternativas prontas. Outras perguntas sobre aspectos pontuais recomendam que a resposta se baseie no que se sabe ou se ouviu falar, no entanto, mais uma vez, as alternativas limitam as respostas. Em outros casos, é apresentada ao respondente uma afirmativa sobre nuances da reforma da previdência ou uma informação assertiva (é assim) e se demanda uma resposta que indique a anuência ou não com o que se apresenta e em qual grau. As perguntas finais são formuladas com base em premissas (p. ex.: Caso não seja possível aumentar impostos para complementar os recursos da Previdência, o governo deveria...) que indicam a existência de vozes diferentes àquelas apresentadas nas alternativas, ainda que a pergunta em si demonstre uma refutação à premissa. 
As Perspectivas para a economia em 2020 (\#11) originam-se de duas perguntas, sendo que a segunda se subdivide e questiona sobre 15 aspectos econômicos, conforme exemplo:

P2A - Pensando no que o(a) sr(a) sabe ou ouviu falar sobre as políticas adotadas pelo governo Jair Bolsonaro em 2019, gostaria de saber se o(a) sr(a) concorda ou discorda de cada uma delas: Redução da taxa básica de juros (SELIC)

Concorda totalmente; Concorda em parte; Não concorda nem discorda; Discorda em parte; Discorda totalmente / Não sabe/Não respondeu

Mais uma vez as alternativas limitam as manifestações opinativas, dando pequena liberdade para a manifestação da gradação. Nas duas questões, demanda-se do inquerido uma apreciação sobre o tema da pergunta.

Finalmente, sete perguntas sondaram os Problemas e prioridades do pais para 2020 (\#14).

P5A - E considerando o que aconteceu no primeiro ano de governo do presidente Jair Bolsonaro, qual dos seguintes problemas o(a) sr(a) considera que melhorou mais? (1 ${ }^{\circ}$ lugar)

Burocracia / Endividamento dos governos Federal e estaduais (déficits fiscais) / Déficit da previdência / Falta de opções de cultura e lazer / Deficiência no fornecimento de energia elétrica / Baixa qualidade das estradas/rodovias / Juros elevados / Salários baixos / Seca/Falta de água / Intolerância às minorias / Enfraquecimento das instituições democráticas / Nenhum destes/Outros / Não sabe/Não respondeu

A pesquisa é assinalada pelo emprego de recursos de engajamento, especialmente o monoglóssico, para apresentar certas informações com assertividade, como no caso do exemplo: antes havia problemas; alguns problemas melhoraram. Como vimos anteriormente, as alternativas restringem a abrangência da expressão da opinião.

Assim, concluímos que as questões de pesquisas de opinião solicitam com maior recorrência respostas apreciativas, indicação do grau da apreciação e manifestação do engajamento que o(a) respondente mantém com o que se expõe na pergunta ou se propõe nas alternativas. As perguntas tendem a apresentar o recurso avaliativo de engajamento 
para indicar a existência de outras vozes, mas sempre em estado de contração ou de fechamento do espaço de negociação. Isso parece conduzir e influenciar a resposta do entrevistado, limitando a opinião àquilo que foi considerado a priori pela equipe de elaboração da pesquisa.

A seguir, apresentamos, descrevemos e diferenciamos os tipos de gráficos mapeados em nossa análise, discutindo algumas marcas avaliativas que parecem ser inerentes à simbolização técnica.

Os tipos de imagem e as marcas avaliativas inscritas inerentes e não inerentes

Encontramos em nossa amostra três grupos de imagem (Figura 5): i) visualização de dados: representações de dados abstratos, como valores numéricos e dados temporais (gráficos, tabelas, p. ex.); ii) diagrama: representações abstratas de ideias, conceitos e processos por meio de setas, layout, orientação de leitura e orientação temporal e espacial; e iii) fotografia: capturas de elementos visíveis a olho $\mathrm{nu}^{12}$. Para o grupo visualização de dados, encontramos quatro subtipos: i) gráficos de linhas; ii) gráficos de barras (horizontais e verticais); iii) gráfico pizza; e iv) tabela.

Figura 5 - Tipos de imagens do corpus

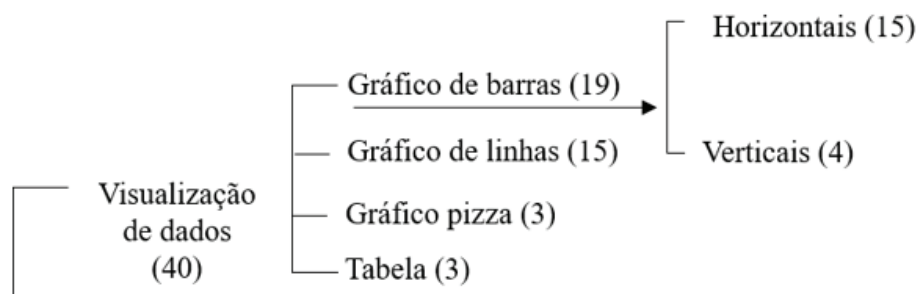

Diagrama (1)

Fotografia (4)

Fonte: elaborada pelas autoras.

12. Essa categorização tem por base Hullman e Bach (2018). 
A visualização de dados predomina $(88,8 \%)$, com destaque para gráficos de barras $(47,5 \%)$ e gráficos de linhas (37,5\%). Na Figura 6, apresentamos os exemplos mais recorrentes em nossa amostra.

Figura 6 - Gráficos mais recorrentes na amostra

Gráfico de barras horizontais

a)

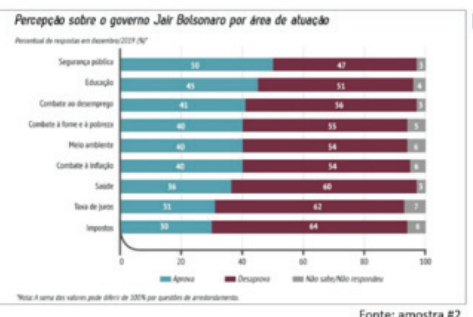

Gráfico de barras verticais

c)

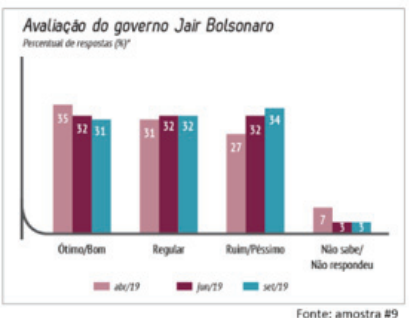

Gráfico de linhas

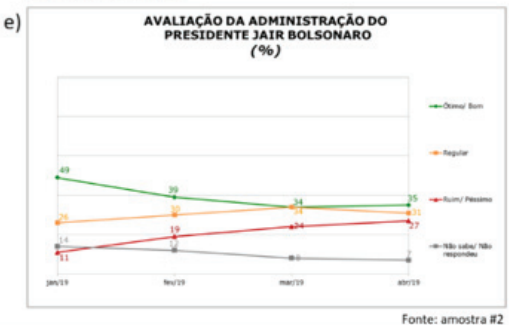

b) PROBLEMAS QUE VÃO MELHORAR EM 2020

Cinco mais escolhidos (\% dos respondentes)

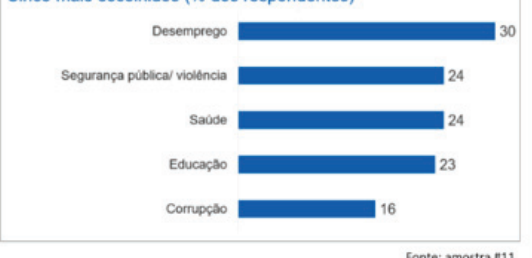

d)

EXPECTATIVA PARAA ECONOMIA EM 2020
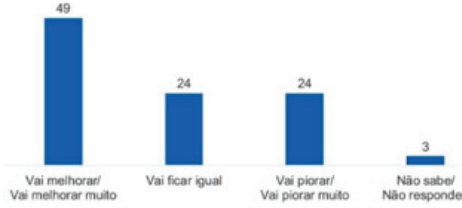

Fonte: amostra \#11

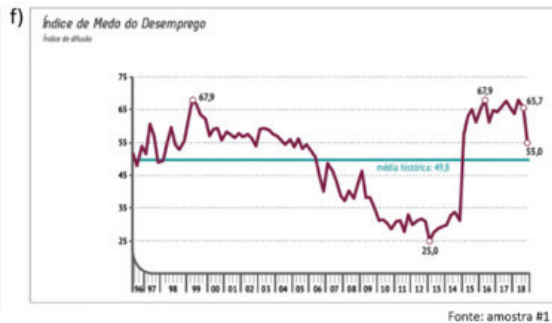

Fonte: Ibope Inteligência Pesquisas e Consultoria LTD. (2020). Ibope Inteligência. https://www. ibopeinteligencia.com/institucional/ibope-inteligencia

Em nossa amostra, os gráficos de barras horizontais informam sobre a proporção de resposta para cada alternativa (no eixo horizontal) e as variáveis investigadas (eixo vertical) (Figura 6a) ou, como na Figura $6 \mathrm{~b}$, o eixo vertical apresenta as variáveis enquanto o eixo horizontal apresenta o valor absoluto de escolha de cada variável. Gráficos de barra 
horizontal do primeiro tipo (6a) suscitam comparação no eixo vertical e no eixo horizontal; os do segundo tipo (6b) suscitam comparação somente no eixo vertical.

Os gráficos de barras verticais (Figura 6c) condensam três tipos de informações: i) proporção de resposta para cada alternativa (eixo vertical); ii) alternativas/opções de variáveis (eixo horizontal); e iii) proporção de resposta para cada alternativa em diferentes momentos históricos (agrupamento das barras no eixo horizontal). Gráficos do tipo $6 \mathrm{~d}$ condensam apenas as informações i e ii.

A forma dos gráficos de barras depende diretamente de inscrições avaliativas de gradação. Entretanto, a gradação ocorre de maneiras distintas e que podem se sobrepor, potencializando a valoração inscrita - e também a evocada -, conforme o tipo de gráfico de barras e o nível de leitura. Para tornar didático esse último ponto, dividiremos a leitura em: i) leitura ampla; e ii) leitura particularizada. Vale destacar que, sem testes específicos e um estudo extenso, não acreditamos ser possível identificar qual nível de leitura ocorre primeiramente ou é predominante.

Em gráficos de barras horizontais, em leitura ampla, a ordenação ${ }^{13}$ surge como uma nova subcategoria de força [quantificação: proximidade: ordenação], pois devido ao padrão de leitura ocidental (esquerda $\rightarrow$ direita; topo $\rightarrow$ base), toda informação que estiver mais à direita e mais acima tenderá a ser apreendida primeiro, logo, estará mais próxima do leitor. Em leitura particularizada, o leitor pode inferir uma valoração quantitativa [força: quantificação: massa/montante], informada pelo tamanho das barras (6b) ou das segmentações das barras (6a). A percepção quantitativa dos dados, contudo, é relativa e dependente da comparação com outras barras ou segmentos de barra.

Nos gráficos de barras verticais, em leitura ampla, novamente, a ordenação ocorre como uma marca de força [quantificação: proximidade: ordenação]. Em gráficos como 6c, a ordenação segue o critério de temporalidade e de apresentação das alternativas ao respondente; em $6 \mathrm{~d}$ a ordenação condiz à ordem de apresentação das alternativas. 
Destacamos que nesses casos a ordenação é não marcada, pois segue padrões de leitura e de apresentação de dados consolidados socialmente. Em caso de ordenação marcada, teríamos uma marca de engajamento autoral.

Em 6c, a quantificação por ordenação parece ser amenizada pela quantificação por número, expressa por uma subcategoria específica que denominaremos agrupamento. Nesse caso, o número de grupos revela uma valoração quantitativa. Quando é feita a leitura estreita, é o número de elementos em cada grupo que revela uma marca quantitativa, expressa, então, pelo tamanho e quantidade de barras em relação às demais do grupo. Em 6d, a leitura estreita revela a gradação de quantidade pelo tamanho das barras. Aqui, a expressão da gradação também depende do nível de leitura e das comparações conduzidas pelo leitor ou a ele sugestionadas.

Gráficos de linha (Figura 6e e 6f), em geral, apresentam valores referentes ao cruzamento de informações independentes (eixo x) com informações dependentes (eixo y). Sendo assim, as linhas apresentam os picos do eixo y, valores mutáveis, conforme cada variável de x, valores fixos. Em nossa amostra, todos os gráficos desse tipo apresentam no eixo $x$ informações temporais (anos ou meses) e no eixo y escalas de valores (de 0 a 100). Gráficos como 6e agrupam várias linhas, ou seja, apresentam a relação tempo x valor para diferentes alternativas de resposta. Gráficos como $6 \mathrm{f}$ apresentam somente uma linha, a qual, em nossa amostra, indica os valores de um índice ao longo do tempo.

Nos gráficos de linha, novamente a gradação aparece como marca avaliativa inerente. No caso de 6e, em leitura ampla, a repetição das linhas sinaliza força em termos de quantificação das variáveis analisadas, indicada pelo número de itens avulsos (em oposição a número por agrupamento). Em leitura mais estrita, cada destaque (ponto) sobre a linha, indicativo do pico do valor de x no eixo y, também revela uma gradação de força [quantificação: número], aludindo à quantidade de variáveis independentes. Em leitura particularizada, o destaque de cada linha revela outra marca gradativa, a qual entendemos como sendo de força [quantificação: extensão: distribuição: posição], pois, de acordo, com o entendimento socialmente difundido, os picos mais altos representarão valores maiores do que os mais baixos. Essa marca de quantificação por posição ocorre tanto em 6e quanto em $6 f$. 
Gráficos pizza e tabelas têm menor recorrência em nossa amostra. Os gráficos pizza também apresentam uma marca intrínseca de avaliação por gradação. Ela se expressa em termos de força, quantificando a massa/montante de cada parcela da "pizza". As tabelas que ocorrem em nossa amostra não apresentam recursos imagéticos que reflitam marcas avaliativas inerentes.

Outro tipo de imagem que encontramos é o diagrama, que talvez seja a imagem técnica mais aberta à ação autoral. Para Mason, Morphet e Prosalendis (2006), os diagramas são imagens científicas altamente permeadas pela ideologia e pelas escolhas subjetivas do autor quanto à representação visual de um conceito. Por isso, defenderemos que os diagramas apresentam o engajamento como uma marca avaliativa inerente.

Além das marcas avaliativas inscritas inerentes encontramos marcas inscritas não inerentes, deliberadamente empregadas para atingir propósitos específicos. Especialmente nos casos de gradação inscrita inerente de força [quantificação], expressões simultâneas de engajamento podem sugestionar a percepção dos dados. Por exemplo, em 6a, 6c e 6e, o emprego de cores parece ter propósito diferencial, mas em 6e a intertextualidade com as cores do semáforo sugestiona apreciação dos dados (bons, medianos ou ruins). Assim, dependendo do conhecimento empírico do leitor, as cores agem como Gatilho e os dados como Afetado.

Em gráficos como 6f, a inclusão seletiva de sinais em alguns picos conduz à relativização do dado mais recente em relação a dados anteriores e não a valores da escala apresentada no eixo y. Ademais, a inserção de uma linha indicando a média histórica sugere que o dado mais recente seja comparado a esse valor médio, evocando apreciação.

Desse modo, podemos concluir que a gradação é uma marca avaliativa recorrente e necessária para a representação de dados por meio de imagens técnicas, especialmente no caso de gráficos. Outras marcas avaliativas, no entanto, podem ser inscritas, a fim de conduzir a leitura dos dados, restringindo o manancial de dados efetivamente lidos, o que pode alterar os efeitos avaliativos evocados no leitor. 
A seguir, veremos como a recepção do texto de divulgação da opinião pública pode ser condicionada pelo arranjo verbo-visual.

\section{Marcas avaliativas em textos que divulgam a opinião pública}

As considerações desta seção baseiam-se na classificação que fizemos das pesquisas de opinião de nossa amostra. No Grupo 1 (\#1; \#4 e \#7), percebemos engajamento autoral: i) nas manchetes $^{14}$, ao destacarem o índice de medo do desemprego e apagarem o índice de satisfação com a vida; ii) em \#4, por não incluir o gráfico relativo ao índice de satisfação com a vida; iii) em \#7, por apresentar os dados em diagrama, empregando recursos como tamanho da fonte e cor para destacar os dados mais recentes.

No Grupo 2 (\#2; \#5; \#9 e \#13), a pesquisa \#2 mostra uma imagem realística (Figura 7a): o presidente Jair Bolsonaro e o então Ministro da Casa Civil, órgão diretamente ligado ao presidente, em conversa ao pé do ouvido. A distância social média e a escolha da imagem revelam engajamento heteroglóssico [expressão marcada] e a expressão facial do presidente inscreve uma atitude [afeto: insatisfação]. O primeiro gráfico de todas as pesquisas concerne aos resultados da pergunta sobre a avaliação do governo do presidente [afeto: apreciação]. As manchetes, entretanto, sugerem principalmente julgamento (avaliação positiva e negativa de Jair Bolsonaro em \#2, avaliação negativa e confiança no presidente em \#5 e popularidade do presidente em \#9); somente \#13 indica uma apreciação (negativa) da administração. Percebemos um esforço em construir a percepção de governo centrada na agência de Jair Bolsonaro. 
Figura 7 - Imagens realísticas da amostra

a)

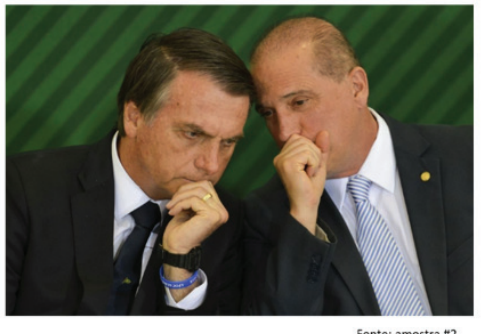

Fonte: amostra \#2

c)

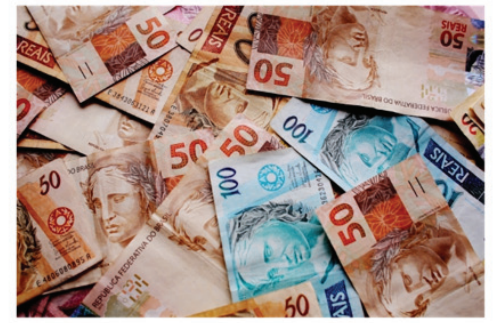

b)

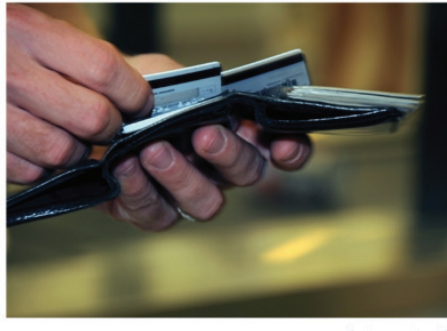

Fonte: amostra \#6

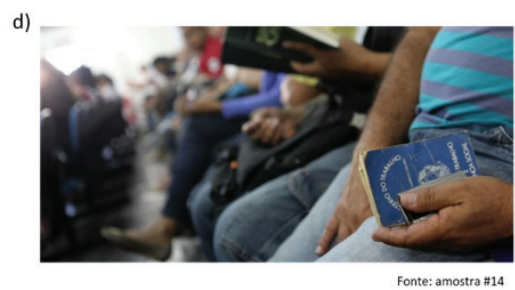

Fonte: amostra \#10

Fonte: Ibope Inteligência Pesquisas e Consultoria LTD. (2020). Ibope Inteligência. https://www. ibopeinteligencia.com/institucional/ibope-inteligencia

As cinco perguntas que integram as pesquisas do Grupo 3 (\#3; \#6; \#10; \#12) são sintetizadas em um único gráfico que mostra o índice de confiança do consumidor. As manchetes indicam o comportamento do índice atual em relação ao anterior. Em \#6, a marca gradativa fusionada no verbo cair e o engajamento revelado por novamente mantêm uma relação de complementaridade com a gradação [foco: especificação: completude] inscrita na imagem de uma carteira vazia entre duas mãos (Figura $7 b$ ). O título e a imagem revelam engajamento da equipe editorial. Esse arranjo pode evocar, p. ex., avaliações de in/satisfação e/ou de in/segurança no leitor [afeto]. Em \#12, há mais sinais de engajamento: nenhum gráfico é apresentado, a manchete indica que a confiança do consumidor continua praticamente estável e uma imagem realística (Figura 7c) enquadra uma grande quantidade de cédulas de 50 reais e duas de 100 reais espalhadas [gradação: quantidade: número] e [extensão: proximidade]. O enquadramento indica que o assunto é dinheiro, já o número de cédulas de 100 reais em relação às de 50 reais parece indicar que o poder de compra não está em sua máxima potência. 
O texto de divulgação da pesquisa \#8 (Grupo 4), reporta somente uma de 19 perguntas, referente à necessidade ou não de reforma da previdência. Nesse caso, os demais resultados são brevemente apresentados no texto que explica a pesquisa.

O texto \#11 (Grupo 5) parece ser o mais neutro, pois apresenta a sequência de gráficos conforme as perguntas foram realizadas. Entretanto, a manchete enquadra o resultado de uma das perguntas somente. Além disso, um dos gráficos, sem qualquer nota ou legenda, apresenta apenas as cinco políticas governamentais mais votadas de 15 sondadas. Outro gráfico pontua que apresenta somente as cinco variáveis mais votadas. Tudo isso indica marcas de engajamento editorial, em que alguns dados são apresentados como sendo todos os dados.

No texto \#14 (Grupo 6), uma imagem realística (Figura 7d) apresenta em destaque uma pessoa sentada em uma fila, enquadrada a partir do peito, segurando uma carteira de trabalho [gradação: especificação: claridade e completude]. Esse destaque dado ao desemprego se conecta à manchete, indicando-o como a maior prioridade/problema para 2020. O primeiro gráfico, contudo, revela que a educação aparece em igual porcentagem que o desemprego como uma prioridade. Os demais gráficos e tabelas desse texto trazem comparações com os anos anteriores e alguns resultados de acordo com características específicas dos respondentes.

Essa análise comprova que a pesquisa de opinião pública publicada gera insumos para o pensar e nem de perto "entrega" os dados conforme foram coletados. Por isso, o engajamento é a categoria avaliativa que mais se destaca quando analisamos o arranjo dos textos multimodais de divulgação de pesquisas de opinião.

\section{Considerações Finais}

Neste estudo, partimos da premissa de que o amplo emprego de recursos visuais técnicos em pesquisa de opinião pública publicada visaria a um apagamento, pelo menos em nível superficial, de indícios subjetivos inerentes à prática discursiva em questão, especialmente os de teor avaliativo, e a uma homogeneização discursiva com propósito de obter maior confiabilidade (Bourdieu, 1973; Tarde, 2005). 
O desenvolvimento de nossa pesquisa legitimou a consistência do referencial teórico-metodológico que adotamos, o qual nos permitiu investigar significados do sistema semântico-discursivo revelados na léxico-gramática visual e verbal, inclusive, consentindo que nossa pesquisa contribua com um pequeno avanço no campo dos estudos de gêneros multimodais e da avaliatividade, pela abordagem de imagens técnicas e pela descoberta de categorias específicas de tal materialidade linguística.

Por meio desta investigação, pudemos concluir que pesquisas de opinião pública tendem a apurar, principalmente, o grau de apreciação do respondente em relação à certos temas e o engajamento que mantém com assertivas expostas nas perguntas e/ou alternativas. Também mapeamos os tipos de imagens recorrentes em textos que divulgam pesquisas de opinião pública e as marcas avaliativas inscritas. Assim, descobrimos que existem marcas avaliativas inerentes, de consenso social, sem as quais um texto visual técnico não se sustentaria, e marcas não inerentes, inscritas por desígnios particulares, oriundos especialmente das instâncias de produção e de distribuição das pesquisas de opinião pública. Outro resultado importante indica que o arranjo multimodal do texto de divulgação da pesquisa de opinião pública é decisivo para a manifestação avaliativa. Por exemplo, a inserção pontual de imagens realísticas; os destaques e apagamentos de dados da pesquisa no conteúdo das manchetes; a inconstância da apresentação dos dados da pesquisa em gráficos condensados ou, pelo contrário, dilatados, sem um padrão retórico reconhecível; e as inscrições de marcas não inerentes, destacam o engajamento autoral nessa etapa do processo de pesquisa da opinião pública dedicado à apresentação dos dados ao leitor.

As diversas camadas e possibilidades de percurso de leitura de textos multimodais complexificam a percepção do potencial multissignificativo de alguns posicionamentos, algo que pode, inclusive, ser usado em favor da dissipação da subjetividade. Nosso estudo, contudo, "entrega" algumas das manifestações subjetivas que entrecortam um texto aparentemente destinado ao relato estatístico factual e revelam como imagens técnicas em textos de divulgação de opinião pública podem sutilmente se tornar em insumo para direcionar o pensar e o agir público, no sentido trazido por Gomes (2001). 
A opinião pública, da coleta à divulgação, é sutilmente construída, e a Avaliatividade tem papel essencial nesse processo. Deste estudo, esperamos que decorram reflexões e expedientes importantes para o ensino e a leitura informada de textos multimodais em que figuram imagens técnicas.

\section{Contribuição dos autores}

Nós, Cristiane Salete Florek e Sara Regina Scotta Cabral, declaramos, para os devidos fins, que ambas participamos da conceptualização do estudo, metodologia, desenho do estudo, análise formal dos dados, análise estatística dos dados, aquisição de financiamento, administração do projeto, supervisão do projeto, coleta dos dados, geração dos dados, validação dos dados, edição e visualização dos dados, escrita do artigo e edição final do artigo submetido e aprovado para publicação na Revista Delta, intitulado "Avaliatividade verbal e visual em textos que divulgam pesquisas de opinião pública". Sendo assim, aprovamos a versão final do manuscrito e somos responsáveis por todos os seus aspectos, incluindo a garantia de sua precisão e integridade.

(X) Declaramos não ter qualquer conflito de interesse, em potencial, neste estudo.

\section{Referências bibliográficas}

Bourdieu, P. (1973). L'opinion publique n'existe pas. Les temps modernes, 29(318), 1292-1309.

Confederação Nacional da Indústria. (2020). Conheça a CNI. http://www. portaldaindustria.com.br/cni/.

Confederação Nacional da Indústria. (2010). Metodologia da pesquisa CNI-IBOPE. http://www.ipeadata.gov.br/doc/metodologiaCNIibope. pdf.

Economou, D. (2009). Photos in the news: appraisal analysis of visual semiosis and visual-verbal intersemiosis. $\mathrm{PhD}$ thesis, University of Sydney, Sydney Digital Theses. http://hdl.handle.net/2123/5740.

Florek, C. (2017). Marcas avaliativas em imagens jornalísticas. Entretextos, $17(2), 195-230$.

Florek, C. (2018). Um resumo acadêmico gráfico vale mais do que mil palavras: análise crítica de um gênero multimodal polivalente. Tese de Doutorado. Manancial, Repositório Digital da Universidade Federal de Santa Maria. http://repositorio.ufsm.br/handle/1/16387. 
Gomes, W. (2001). Opinião pública política hoje: uma investigação preliminar. In A. Fausto Neto et al. (Eds.). Práticas mediáticas e espaço público (Vol. 1, pp. 61-82). Porto Alegre: Editora da PUC/RS.

Halliday, M. A. K., \& Matthiessen, C. (2014). Halliday's Introduction to Functional Grammar (4th ed.). Oxon and New York: Routledge.

Hullman, J., \& Bach, B. (2018). Picturing science: Design patterns in graphical abstracts. In G. Stapleton, F. Bellucci, A. Moktefi, P. Chapman, \& S. Perez-Kriz (Eds.). Diagrammatic Representation and Inference - 10th International Conference, Diagrams 2018, Proceedings (pp. 183-200). (Lecture Notes in Computer Science (including subseries Lecture Notes in Artificial Intelligence and Lecture Notes in Bioinformatics); Vol. 10871 LNAI). Springer Verlag. https://doi.org/10.1007/978-3-319-91376-6_19.

Ibope Inteligência Pesquisas e Consultoria LTD. (2020). Ibope Inteligência. $\mathrm{https}$ ://www.ibopeinteligencia.com/institucional/ibope-inteligencia.

Kress, G., \& Van Leeuwen, T. (2006). Reading images: the grammar of visual design. London: Routledge.

Martin, J. R., \& White, P. R. R. (2005). The language of evaluation: appraisal in English. New York: Continuum.

Mason, R., Morphet, T., \& Prosalendis, S. (2006). Reading scientific images: the iconography of evolution. Cape Town: HSRC Press.

Ninin, M. O. G., \& Barbara, L. (2013). Engajamento na perspectiva linguística sistêmico-funcional em trabalhos de conclusão de curso de Letras. Trabalhos em Linguística Aplicada, 52(1), 127-146.

Tarde, G. (2005). A opinião e as massas. São Paulo: Martins Fontes.

Recebido em: 19/06/2020

Aprovado em: 23/11/2020 